\title{
UMA ANÁlISE CRÍTICA DE GÊNERO DE ARTIGOS AUDIOVISUAIS DE PESQUISA: INTERAÇÃO E RELAÇÕES SOCIAIS
}

\author{
Thales Cardoso da Silva
}

Submetido em 07 de junho de 2018.

Aceito para publicação em 02 de outubro de 2018.

Cadernos do IL, Porto Alegre, n. ${ }^{\circ}$ 56, novembro. p. 241-256

\section{POLÍTICA DE DIREITO AUTORAL}

Autores que publicam nesta revista concordam com os seguintes termos:

(a) Os autores mantêm os direitos autorais e concedem à revista o direito de primeira publicação, com o trabalho simultaneamente licenciado sob a Creative Commons Attribution License, permitindo o compartilhamento do trabalho com reconhecimento da autoria do trabalho e publicação inicial nesta revista.

(b) Os autores têm autorização para assumir contratos adicionais separadamente, para distribuição não exclusiva da versão do trabalho publicada nesta revista (ex.: publicar em repositório institucional ou como capítulo de livro), com reconhecimento de autoria e publicação inicial nesta revista.

(c) Os autores têm permissão e são estimulados a publicar e distribuir seu trabalho online (ex.: em repositórios institucionais ou na sua página pessoal) a qualquer ponto antes ou durante o processo editorial, já que isso pode gerar alterações produtivas, bem como aumentar o impacto e a citação do trabalho publicado.

(d) Os autores estão conscientes de que a revista não se responsabiliza pela solicitação ou pelo pagamento de direitos autorais referentes às imagens incorporadas ao artigo. A obtenção de autorização para a publicação de imagens, de autoria do próprio autor do artigo ou de terceiros, é de responsabilidade do autor. Por esta razão, para todos os artigos que contenham imagens, o autor deve ter uma autorização do uso da imagem, sem qualquer ônus financeiro para os Cadernos do IL.

\section{POLÍTICA DE ACESSO LIVRE}

Esta revista oferece acesso livre imediato ao seu conteúdo, seguindo o princípio de que disponibilizar gratuitamente o conhecimento científico ao público proporciona sua democratização. 


\title{
UMA ANÁLISE CRÍTICA DE GÊNERO DE ARTIGOS AUDIOVISUAIS DE PESQUISA: INTERAÇÃO E RELAÇÕES SOCIAIS
}

\author{
A CRITICAL GENRE ANALYSIS OF AUDIOVISUAL \\ RESEARCH ARTICLES: INTERACTION AND SOCIAL \\ RELATIONS
}

Thales Cardoso da Silva ${ }^{1}$

\begin{abstract}
RESUMO: Journal of Visualized Experiments, um periódico digital fundado em 2006, acrescentou às publicações científicas novas possibilidades semióticas: o áudio e o vídeo. $O$ principal objetivo do presente artigo é verificar como os artigos publicados neste periódico se configuram interpessoalmente (HALLIDAY, 1994, 2004, 2014; KRESS, van LEEUWEN, 2006), na perspectiva da Análise Crítica de Gênero (MOTTA-ROTH, 2006, 2008; MOTTA-ROTH; HEBERLE, 2015), considerando a natureza multimodal do gênero. O corpus compreende um total de 10 artigos audiovisuais de pesquisa, selecionados pelos critérios recentidade, acesso e área do conhecimento. Os artigos forma analisados em modo oracional e função de fala, contato, poder, distância social e atitude. Conclui-se que artigos audiovisuais de pesquisa possuem uma organização própria se comparados aos tradicionais artigos acadêmicos escritos.
\end{abstract}

PALAVRAS-CHAVE: Análise crítica de gênero; Linguística sistêmico-funcional; Artigos audiovisuais de pesquisa; Inglês para fins específicos.

ABSTRACT: Journal of Visualized Experiments, a digital journal founded in 2006, added to scientific publications new semiotic possibilities: the audio and video. The main objective of the resent paper is to verify how articles published on this journal are configured interpersonally (HALLIDAY, 1994, 2004, 2014; KRESS, van LEEUWEN, 2006), in the perspective of the Critical Genre Analysis (MOTTA-ROTH, 2006, 2008; MOTTA-ROTH; HEBERLE, 2015), considering the multimodal nature of the genre. The corpus comprehends a total of 10 audiovisual research articles, selected by the criteria of recency, access and area of knowledge. The articles were analyzed in mood and speech function, contact, power, social distance and attitude. As result, audiovisual research articles have its own organization when compared to traditional written papers.

KEYWORDS: Critical genre analysis; Systemic-functional linguistics; Audiovisual research articles; English for specific purposes.

\section{Introdução}

Artigos acadêmicos experimentais constituem um gênero discursivo tradicional no contexto acadêmico. Esse gênero serve, resumidamente, como uma ferramenta adotada por cientistas com o intuito de reportar descobertas científicas à esfera acadêmica, de forma a torná-las públicas (SWALES, 1990; 2004), usualmente apresentando predominância no recurso semiótico escrito. A organização retórica típica

\footnotetext{
1 *Mestre e doutorando em Estudos Linguísticos pela Universidade Federal de Santa Maria. Trabalho fomentado pela Coordenação de Aperfeiçoamento de Pessoal de Nível Superior. E-mail para contato: thalescss@gmail.com.
} 
de tais artigos segue, em essência, o padrão IMRD, consistindo em Introdução, Metodologia, Resultados e Discussão (SWALES, 1990, 2004). É importante ressaltar que a origem dos artigos acadêmicos é geralmente associada ao contexto impresso e “inseparavelmente (...) à história dos periódicos científicos" (HENDGES, 2008, p. 18).

Fairclough (2003) aponta que gêneros discursivos acompanham as possibilidades tecnológicas e sociais. Segundo o autor (FAIRCLOUGH, 2003, p. 77), novas tecnologias de comunicação, principalmente tecnologias de informações eletrônicas como a internet, aumentaram significativamente as possibilidades de comunicação e interação humana. Como consequência, o surgimento de novas tecnologias de comunicação se torna um fator decisivo na mudança e desenvolvimento dos gêneros discursivos (FAIRCLOUGH, 2003, p. 77).

Ao encontro disso, Shepherd e Watters (1998) apontam que, por vezes, as mudanças que novas tecnologias trazem aos gêneros discursivos podem ser tão extensas, que levam à emergência de novos gêneros. Shepherd e Waters (1998) propõem o conceito de cibergêneros (cybergenres), de forma a definir uma nova classe de gêneros, resultantes da influência do computador e da internet nos gêneros do discurso, e muitas vezes, passíveis de materialização apenas no contexto digital.

Como um exemplo da influência da tecnologia no contexto acadêmico, no ano de 2006, foi fundado o periódico JoVE, Journal of Visualized Experiments, um periódico baseado no contexto digital. Tal periódico acrescentou às publicações científicas novas possibilidades semióticas: o áudio e o vídeo. Por meio de tais tecnologias de significado, procedimentos são demonstrados, expostos e explicados em termos de tempo, espaço e maneira (SILVA, 2015, SILVA et. al., 2015). Desde seu surgimento, o periódico $J o V E$ mostrou-se uma alternativa inovadora às publicações científicas, principalmente por utilizar recursos semióticos eventualmente explorados em publicações acadêmicas. Devido ao caráter recente de publicações acadêmicas em tal formato, estudos acerca dos artigos audiovisuais de pesquisa na área de linguística aplicada encontram-se em fase inicial (HENDGES, 2010; 2011a; 2012b; SILVA, 2015; SILVA et al., 2015, SOUZA, 2015; MILANI, 2015). Um estudo com um enfoque especificamente nos significados interpessoais deste gênero é relevante, pois mapear tais significados traz à luz como se dá a interação autor/leitor, e como os mesmos interagem na troca de conhecimentos acadêmicos neste gênero emergente, assim estabelecendo relações sociais e de poder.

O crescimento do periódico JoVE também demonstra a relevância de seu estudo em termos de número de artigos publicados por edição (JoVE; 2015a), além da abrangência das áreas do conhecimento contempladas (de subáreas essencialmente biológicas em 2007 (HENDGES, 2010) para novas áreas do conhecimento, como química, engenharia e psicologia em 2015). Assim, o estudo deste formato de publicação pode contribuir significativamente para a área de Inglês para Fins Acadêmicos, de forma a auxiliar na elaboração de materiais e lições que considerem este formato de publicação, uma vez que esses artigos mobilizam multiletramentos (CAZDEN et al., 1996), dentre os quais estão o letramento digital, o letramento multimodal, o letramento científico e o letramento em língua estrangeira.

$O$ estudo deste gênero também pode contribuir na informação de pesquisadores inexperientes a respeito da produção e consumo desse gênero. Uma vez que os artigos audiovisuais de pesquisa são produzidos unicamente em língua inglesa, mas por cientistas e autores nativos e não nativos dessa língua, este estudo pode ser significativo para incrementar discussões a respeito do inglês como uma língua internacional no 
contexto acadêmico (RAJAGOPALAN, 2004). Finalmente, o estudo de tal formato de publicação científica pode auxiliar a situar este formato ainda pouco estudado como um gênero acadêmico tradicional.

Dessa forma, o principal objetivo do presente estudo é verificar como se estabelecem marcas de interação e relações sociais (HALLIDAY, 1994, 2004, 2014; KRESS, van LEEUWEN, 2006) nos artigos publicados no periódico JoVE, adotando procedimentos e categorias de análise que reconheçam a natureza multimodal do gênero, por meio dos dois principais modos semióticos presentes no gênero: o verbal oral e o visual dinâmico.

Sendo assim, os objetivos específicos deste artigo são:

I. Examinar os significados interpessoais veiculados no recurso semiótico verbal (oral), sob a ótica sistêmico-funcional (HALLIDAY, 1994, 2004), verificando a ocorrência de padrões.

II. Examinar os significados interativos veiculados no recurso semiótico visual (imagens em movimento), sob a ótica sistêmico-funcional (KRESS, van LEEUWEN, 2006), verificando a ocorrência de padrões.

III. Traçar um perfil da forma em que tais padrões (se encontrados) são distribuídos ao longo dos artigos, buscando pistas a respeito da organização retórica do gênero, considerando ambos os componentes semióticos.

A seguir, na seção 2, apresentamos a fundamentação teórica que embasa 0 presente artigo: a Análise Crítica de Gênero (MOTTA-ROTH, 2006; 2008; MOTTAROTH; HEBERLE, 2015) e a Linguística Sistêmico Funcional (HALLIDAY, 1994; 2004; 2014; KRESS; van LEEUWEN, 2006; IEDEMA, 2001).

\section{Fundamentação teórica}

A seguir, apresentamos os principais conceitos norteadores à análise proposta no presente artigo. Primeiramente, são apresentados conceitos e princípios abarcados pela Análise Crítica de Gênero. Em seguida, são discutidas as duas ferramentas da Linguística Sistêmico-Funcional utilizadas na análise aqui apresentada: a Gramática Sistêmico Funcional, utilizada na análise do componente semiótico verbal, e a Gramática do Design Visual, utilizada na análise do componente semiótico visual ambas com enfoque na metafunção interpessoal.

A Análise Crítica de Gênero (MOTTA-ROTH, 2006; 2008; MOTTA-ROTH; HEBERLE, 2015), a fim de investigar o funcionamento dos gêneros do discurso, propõe uma integração de conceitos, ferramentas e procedimentos analíticos pertencentes a três tradições linguísticas: a Análise Crítica do Discurso, a Análise de Gênero e a Linguística Sistêmico-Funcional.

A Análise Crítica do Discurso (FAIRCLOUGH, 1992, 2003) propõe analisar o discurso em três dimensões: a do texto, a do evento discursivo e a da prática discursiva, considerando texto e contexto dimensões indissociáveis do discurso. Nesse sentido, a Análise Crítica do Discurso busca a associação de uma análise linguisticamente orientada a aspectos sociais e políticos pertinentes ao discurso e à linguagem, com base em um aparato teórico-metodológico apropriado à pesquisa social (FAIRCLOUGH, 1992). 
A Análise de Gênero (SWALES, 1990) busca, pela análise linguística, a identificação de regularidades relativas à organização do discurso. Estudos nessa tradição linguística buscam explorar a função dos gêneros discursivos na forma com que indivíduos se engajam em práticas sociais (SWALES, 1990).

A linguística Sistêmico-Funcional contribui com a Análise Crítica de Gênero pela visão da língua em termos de metafunções, nas quais três categorias de significado são realizadas simultaneamente em qualquer concretização da linguagem em uso: a natureza da atividade envolvida (metafunção ideacional), o papel da linguagem na atividade em questão (metafunção textual) e as relações sociais entre os participantes da atividade (metafunção interpessoal). Dessa forma, a linguística Sistêmico-Funcional oferece à Análise Crítica de Gênero uma ferramenta de análise textual que considera o texto e sua estrutura léxico-gramatical como reflexos de escolhas feitas pelos falantes de forma a organizar seu discurso, posicionarem-se como participantes sociais e representarem conceitos, ideias e posicionamentos.

A metafunção interpessoal, foco de análise do presente artigo, busca abarcar relações sociais estabelecidas na linguagem entre as entidades que compõem a troca, vista, neste ponto de vista, como interação (HALLIDAY, 2004, p. 29). São os sistemas de modo oracional e a modalidade que decretam a organização do discurso nesse ponto de vista. $\mathrm{O}$ sistema de Modo diz respeito às estruturas frasais utilizadas para viabilizar a troca efetuada na interação e é o principal ponto léxico-gramatical na metafunção interpessoal, podendo consistir em imperativo, declarativo e interrogativo. A natureza da negociação efetuada através da linguagem é considerada pelo sistema de Funções de Fala, que podem ser: demandar informações, demandar bens e serviços, oferecer informações e oferecer bens e serviços (HALLIDAY, 2004, p. 108). O sistema de Modalidade, outro sistema de importância na metafunção interpessoal, pode ser compreendido como a extensão de validade atribuída ao conteúdo proposicional na oração (HALLIDAY, 2004; p. 116). Modalização diz respeito aos diferentes graus de probabilidade e usualidade (HALLIDAY, 2004; p. 116), enquanto a Modulação se encarrega dos diferentes graus de obrigação e inclinação (HALLIDAY, 2004, p. 116).

Partindo dos estudos de Halliday (1994, 2004, 2014), a Gramática do Design Visual (KRESS; van LEEUWEN, 2006) considera como os elementos retratados em imagens "se combinam em declarações visuais de maior ou menor complexidade e extensão" (KRESS; van LEEUWEN, 2006, p. 1). Neste sentido, toda forma de significação exerce três funções: representacional - aquela de representar o mundo , que corresponde à metafunção ideacional da Gramática Sistêmico-Funcional; composicional - aquela de organizar a interação, que corresponde à metafunção textual; interativa aquela de estabelecer relações entre participantes representados (no texto) e participantes interativos (autor e leitor), que corresponde à metafunção interpessoal.

A metafunção interativa ou interpessoal dá conta das relações entre autor e leitor da imagem, encarregando-se, assim, da representação da relação social entre produtor, leitor e objeto representado (KRESS; van LEEUWEN, 2006, p. 42). Os sistemas a serem analisados nesta perspectiva são os sistemas de contato/interação, distância social, atitude e poder.

A configuração de tais elementos é diretamente associada ao contexto da representação. Nesse sentido, Kress e van Leeuwen (2006) apontam que a modalidade visual baseia-se em padrões historicamente determinados da realidade, ou seja, princípios de realidade. Existe, então, um conjunto de "princípios abstratos que explicam a forma como textos são codificados por grupos sociais específicos, ou por 
contextos institucionais específicos" (KRESS, van LEEUWEN, 2006, p. 164). Tais princípios são denominados coding orientations, - traduzido por Hendges, Nascimento e Marques (2013) como "orientações de codificação" - e são distinguidos em quatro diferentes orientações: naturalista, abstrata, sensorial e tecnológica (KRESS, van LEEUWEN, 2006, p. 165).

Por fim, considerando que o presente estudo lida com textos multimodais dinâmicos (audiovisuais), faz-se necessária uma teoria para fins analíticos que considere a organização e segmentação de textos em tal formato. Iedema (2001) apresenta estratégias analíticas que buscam conectar, em textos multimodais, as maneiras pelas quais cada segundo do texto é costurado ao próximo, criando um todo. A estratégia apresentada pelo autor é derivada de perspectivas sociossemióticas da linguagem, por se preocupar com questões sociopolíticas da linguagem em uso (IEDEMA, 2001).

São seis os níveis de análise propostos por Iedema (2001), que buscam congregar categorias analíticas comumente utilizadas em teorias do cinema e categorias utilizadas em teorias de análise de gênero (IEDEMA, 2001): (1) quadro (menor nível de análise) é o que a análise toma como o retrato saliente da tomada, sendo papel do analista decidir a quantidade de quadros a serem considerados. No nível acima, (2) tomadas são unidades sem cortes de câmera. Acima da tomada, tem-se a (3) cena, que combina tomadas em um único tempo-espaço de forma a criar uma unidade. No nível seguinte, (4) sequências combinam cenas em termos de uma continuidade lógica ou temática, e não em termos de tempo e espaço. No nível acima, sequências se combinam em (5) estágios genéricos ou, nos termos de Swales (1990), "movimentos retóricos", que, por sua vez, compõem o propósito comunicativo do gênero. Assim, os estágios genéricos constituem o (6) gênero em questão.

As categorias propostas por Iedema (2001) serão consideradas no presente estudo no que se refere à segmentação dos textos audiovisuais, especialmente para fins de transcrição e análise do corpus. Apresentamos, na seção a seguir, o percurso metodológico adotado para a análise a que o presente artigo se propõe.

\section{Metodologia}

A metodologia do presente artigo se dá em diferentes estágios. Primeiramente, apresentamos os critérios para seleção do corpus. Após, apresentamos as categorias de análise linguística, em dois pontos: do componente semiótico verbal e do componente semiótico visual. Por fim, apresentamos dados relativos à análise do contexto.

$\mathrm{O}$ corpus do presente artigo compreende um total de 10 artigos audiovisuais de pesquisa publicados no periódico JoVE. Os critérios para seleção do corpus foram (1) recentidade, (2) acesso e (3) área do conhecimento.

Primeiramente, foram selecionados artigos publicados a partir do ano de 2011. A razão por tal escolha se dá pela padronização dos artigos publicados a partir desse ano, em função de mudanças nas Instruções para autores (JoVE, 2015c). Após diversas modificações desde o início das atividades do periódico em 2006, o JoVE adotou, em 2010, uma estrutura específica e única para a aceitação de artigos.

O critério (2), acesso, se dá em função de que o acesso à maior parte do conteúdo do periódico exige uma assinatura paga. Ainda assim, existe uma seção de artigos patrocinados, na qual o acesso aos artigos se dá de forma gratuita. 
O critério (3), área do conhecimento, reflete nossa intenção em considerar características disciplinares e sua influência na organização do gênero. Assim, consideramos artigos de duas áreas de estudo oferecidas pelo periódico: Biologia e Medicina. Tal escolha justifica-se em razão de que, no início do periódico, as publicações se davam em duas seções: Biology e a extinta seção General. Sendo assim, a área de Biologia pode ser considerada como uma área pioneira no periódico, tendo estimulado seu crescimento e sua expansão a novas áreas científicas. A área Medicina, anteriormente publicada na seção Clinical and Translational Medicine, foi acrescentada ao periódico no ano de 2011, mas já é a segunda área que apresenta maior número de artigos publicados (JOVE, 2015h). Assim, a escolha de tais áreas se justifica pela representatividade de ambas no periódico JoVE. Considerando esse critério, foram selecionados 5 artigos publicados em cada área (total de 10 artigos), de maneira que características disciplinares fossem consideradas na análise do gênero em questão.

Para fins da análise do componente semiótico verbal, primeiramente, o corpus foi transcrito, uma vez que originalmente esse componente é oral. Então, cada texto teve suas orações identificadas e parceladas, em termos de orações independentes e orações dependentes. Em seguida, cada oração foi classificada em termos de modo oracional e função de fala. Para a classificação em termos de modo oracional, foram analisados os elementos Sujeito e Finito em cada oração, e sua configuração em termos de modo declarativo, imperativo ou interrogativo. Para a classificação em termos de função de fala, as orações foram analisadas em termos de oferta ou demanda, de informações ou de bens e serviços.

A primeira etapa de análise do componente visual consistiu na transcrição do corpus, de imagens em movimento para imagens estáticas ${ }^{1}$. Para tal, foi considerada a segmentação do vídeo em tomadas - etapas em que o movimento da câmera não é editado, sem cortes (IEDEMA, 2001). Em seguida, cada tomada foi classificada em termos dos sistemas que realizam os significados interativos visuais: contato, poder, distância social e atitude.

Paralelamente à análise linguística, foi guiada uma análise contextual, de forma a informar a presente análise por meio de documentos oficiais fornecidos pelo periódico JoVE a pesquisadores interessados na publicação de seus artigos (Quadro 1). Tal análise funciona de forma a embasar a interpretação dos resultados obtidos na análise linguística, por meio da informação de questões de acesso e participação no gênero em questão, ou seja, relações sociais e relações de poder que permeiam a atividade social aqui explorada.

\begin{tabular}{lll}
\hline Documento & E-Link & Referência \\
\hline Arquivos (Archive) & http://www.jove.com/archive & JOVE, \\
\hline Publicações (Publish) & http://www.jove.com/publish & JOVE, \\
\hline Instruções para Autores & http://www.jove.com/files/Instruct & JOVE, 2015c. \\
\hline
\end{tabular}

\footnotetext{
${ }^{1}$ Temos consciência de que a transformação de imagens em movimento para imagens estáticas acarreta em perda de significados no texto multimodal. Tal escolha foi feita como maneira de ter-se um retrato saliente de cada tomada que compõe o vídeo, para fins de análise. Justificamos tal escolha pelo fato de que abordagens metodológicas à análise de imagens em movimento ainda possuem enfoque em imagens estáticas. Buscamos contribuir com o surgimento de novas abordagens que considerem o texto em movimento.
} 


\begin{tabular}{|c|c|c|}
\hline (Instructions for Authors) & ions_for_Authors.pdf & \\
\hline $\begin{array}{l}\text { Critérios de qualidade para } \\
\text { vídeos produzidos por } \\
\text { autores (Author Produced } \\
\text { Video Quality Criteria) }\end{array}$ & $\begin{array}{l}\text { http://www.jove.com/files/media/ } \\
\text { AuthorProducedCriteria }\end{array}$ & $\begin{array}{l}\text { JOVE, } \\
2015 \mathrm{~d}\end{array}$ \\
\hline Sobre o Periodico (About) & http://www.jove.com/about & $\begin{array}{l}\text { JOVE, } \\
2015 \mathrm{e} .\end{array}$ \\
\hline $\begin{array}{l}\text { Perguntas frequentes } \\
\text { (Frequently Asked } \\
\text { Questions) }\end{array}$ & $\begin{array}{l}\text { http://www.jove.com/publish/sub } \\
\text { mission-faq }\end{array}$ & $\begin{array}{l}\text { JOVE, } \\
2015 f .\end{array}$ \\
\hline $\begin{array}{l}\text { Instituições Contribuidoras } \\
\text { (Contributing Institutions) }\end{array}$ & http://www.jove.com/institutions & JOVE, 2015g. \\
\hline
\end{tabular}

Quadro 1 - Documentos oficiais do periódico JoVE considerados na análise contextual (elaborado pelo autor)

Na seção 4, apresentamos os resultados obtidos por meio da análise apresentada e sua discussão.

\section{Resultados e discussão}

Em termos do componente semiótico verbal, em um total de 1219 orações encontradas, 769 caracterizam-se como orações independentes, enquanto 450 caracterizam-se como orações dependentes (Tabela 1). É possível perceber que, ainda que a maior parte do número total de orações caracterize-se por serem orações independentes (63\% do total de orações), há um grande número de orações dependentes nos artigos analisados (37\%). Pela grande incidência desse tipo de orações no corpus analisado, entendemos que orações dependentes parecem possuir uma função de importância no gênero.

Dos três tipos de Modo oracional possíveis - Declarativo, Imperativo e Interrogativo - predomina o Modo Declarativo em 807 (66\%) das 1219 orações (Tabela 1). Considerando o grande número de orações dependentes e que estas necessariamente assumem o modo declarativo, essa ocorrência poderia ser esperada. Entretanto, quando se trata apenas das orações independentes, nota-se uma presença massiva do Modo imperativo (54\%). Assim, na oração independente, a escolha pelo modo imperativo parece indicar a necessidade de evidenciar comandos, nesse caso, sobre ações a serem executadas para o desenvolvimento de algum protocolo. Tal ocorrência pode ser ligada aos objetivos apresentados pelo periódico, que são a superação da baixa reprodutibilidade acadêmica e a propagação de novas técnicas experimentais (JOVE, 2015e). Assim, a grande ocorrência do modo imperativo aponta que, para atingir seus objetivos, os artigos publicados no periódico utilizam principalmente comandos e instruções, detalhando etapas dos protocolos de pesquisa apresentados.

\begin{tabular}{|c|c|c|c|c|c|c|c|c|}
\hline \multirow{2}{*}{$\begin{array}{c}\text { Modo } \\
\text { oracional }\end{array}$} & \multicolumn{2}{|c|}{$\begin{array}{c}\text { Modo } \\
\text { declarativo }\end{array}$} & \multicolumn{2}{|c|}{$\begin{array}{c}\text { Modo } \\
\text { imperativo }\end{array}$} & \multicolumn{2}{|c|}{$\begin{array}{c}\text { Modo } \\
\text { interrogativo }\end{array}$} & \multicolumn{2}{|c|}{ Total } \\
\hline & $\mathrm{n}$ & $\%$ & $\mathrm{n}$ & $\%$ & $\mathrm{n}$ & $\%$ & $\mathrm{n}$ & $\%$ \\
\hline $\begin{array}{l}\text { Orações } \\
\text { independentes }\end{array}$ & 357 & $29 \%$ & 412 & $34 \%$ & -- & -- & 769 & $63 \%$ \\
\hline
\end{tabular}




\begin{tabular}{|c|c|c|c|c|c|c|c|c|}
\hline $\begin{array}{l}\text { Orações } \\
\text { dependentes }\end{array}$ & 450 & $37 \%$ & -- & & -- & -- & 450 & $37 \%$ \\
\hline Total & 807 & $66 \%$ & 412 & $34 \%$ & -- & -- & 1.219 & $100 \%$ \\
\hline
\end{tabular}

Tabela 1 - Total de orações em termos orações independentes, dependentes e modo oracional

Tais resultados contribuem para evidenciar o princípio de que as funções de fala de (1) fornecer informações, (2) fornecer bens e serviços, (3) demandar informações e (4) demandar bens e serviços ocorrem conforme cada gênero discursivo. Tendo em vista o objetivo do periódico JoVE, é possível hipotetizar que a demanda de bens e serviços seria uma das características dos artigos. De fato, na contabilização das funções de fala das orações independentes, como já sugeriu o predomínio do Modo imperativo, observou-se que 494 (65\%) demandam serviços (Tabela 2). Esse percentual indica que além das 412 orações imperativas, 82 declarativas também executam a função de demandar serviços. Além disso, o destaque para essa função também pode ser percebido pela presença de 8 orações dependentes (2\%) que demandam serviço.

\begin{tabular}{lcccccc}
\hline $\begin{array}{l}\text { Função de } \\
\text { fala básica }\end{array}$ & \multicolumn{2}{c}{ Fornecer informações } & \multicolumn{2}{c}{ Demandar serviços } & \multicolumn{2}{c}{ Total } \\
\hline $\begin{array}{l}\text { Orações } \\
\text { independentes }\end{array}$ & 275 & $23 \%$ & 494 & $40 \%$ & 769 & $63 \%$ \\
$\begin{array}{l}\text { Orações } \\
\text { dependentes }\end{array}$ & 442 & $36 \%$ & 8 & $0,7 \%$ & 450 & $37 \%$ \\
\hline Total & 717 & $59 \%$ & 502 & $40,7 \%$ & 1.219 & $100 \%$ \\
\hline
\end{tabular}

Tabela 2 - Total de orações em termos de função de fala

No somatório total, entretanto, predomina o fornecimento de informações, em 717 orações $(58 \%)$. Esse padrão pode estar relacionado a diferentes motivações da configuração dos artigos publicados no periódico JoVE, como a necessidade de expor questões de propósito, maneira, sequencialidade e explicações - os quais são características da oração dependente - referentes aos procedimentos dos protocolos, apresentados, principalmente, nas orações independentes.

A respeito do componente semiótico visual, foi analisado um total de 482 tomadas. Cada tomada foi analisada em termos de contato (oferta ou demanda), poder (ângulo alto/poder por parte do espectador, ângulo médio/igualdade de poder e ângulo baixo/poder por parte do participante representado), distância (proximidade, distância média e distanciamento) e atitude (envolvimento e desprendimento). Percebeu-se que há predominância (1) na oferta como tipo de contato, totalizando $93 \%$ das tomadas analisadas; (2) no poder por parte do espectador, realizado pelo ângulo alto, totalizando $57 \%$ das tomadas analisadas; e (3) no desprendimento como tipo de atitude, totalizando $57 \%$ do total de tomadas analisadas. A categoria distância social apresenta equilíbrio em suas ocorrências: $43 \%$ das tomadas são caracterizadas pela proximidade, enquanto 45\% são caracterizadas pela distância média (Tabela 3 ). 


\begin{tabular}{|c|c|c|c|c|c|}
\hline \multicolumn{6}{|c|}{ Tipo de contato } \\
\hline \multicolumn{3}{|c|}{ Oferta } & \multicolumn{3}{|c|}{ Demanda } \\
\hline $\mathrm{n}$ & & $\%$ & $\mathrm{n}$ & & $\%$ \\
\hline 451 & & 93 & 31 & & 7 \\
\hline \multicolumn{6}{|c|}{ Poder } \\
\hline \multicolumn{2}{|c|}{ Ângulo alto } & \multicolumn{2}{|c|}{ Ângulo médio } & \multicolumn{2}{|c|}{ Ângulo baixo } \\
\hline $\mathrm{n}$ & $\%$ & $\mathrm{n}$ & $\%$ & $\mathrm{n}$ & $\%$ \\
\hline 279 & 57 & 203 & 43 & -- & -- \\
\hline \multicolumn{6}{|c|}{ Distância } \\
\hline \multicolumn{2}{|c|}{ Proximidade } & \multicolumn{2}{|c|}{ Distância média } & \multicolumn{2}{|c|}{ Distanciamento } \\
\hline $\mathrm{n}$ & $\%$ & $\mathrm{n}$ & $\%$ & $\mathrm{n}$ & $\%$ \\
\hline 207 & 43 & 215 & 45 & 60 & 12 \\
\hline \multicolumn{6}{|c|}{ Tipo de atitude } \\
\hline \multicolumn{3}{|c|}{ Envolvimento } & \multicolumn{3}{|c|}{ Desprendimento } \\
\hline $\mathrm{n}$ & & $\%$ & $\mathrm{n}$ & & $\%$ \\
\hline 209 & & 43 & 273 & & 57 \\
\hline
\end{tabular}

Tabela 3 - Resultados da análise do componente semiótico visual

A predominância da oferta, em termos do tipo de contato, sugere que o componente visual nos artigos analisados possui um enfoque em apresentar procedimentos de pesquisa em termos de instrumento, materiais e/ou objetos a serem utilizados nos experimentos e como os mesmos se localizam e se distribuem espacialmente, bem como etapas a serem seguidas para a reprodução de experimentos. Não há grande ênfase no pesquisador/nos autores do estudo ou no executor do procedimento, ou seja, na interação dos autores como leitor via olhar.

Sendo assim, pode-se dizer que os artigos audiovisuais de pesquisa analisados apresentam uma oferta de informações na forma de "eventos" (KRESS; van LEEUWEN, 2006, p. 64), em que o foco é o Processo Material (ação física) e a Meta (entidade afetada pelo processo) e não o Ator (executor do procedimento), pois deste só vemos braços, mãos, pontas dos dedos. Assim, temos acesso ao que está acontecendo foco da informação ofertada -, mas não ao responsável pelo acontecimento. O Ator é posicionado na função gramatical de agente da passiva, permitindo que seja excluído parcial ou totalmente do evento (KRESS; van LEEUWEN, 2006, p. 64), de forma que a imagem oferece o que é objetivamente essencial para a execução do procedimento.

Além disso, considerando que o periódico busca aproximar pesquisadores e protocolos no sentido de tornar os protocolos mais acessíveis para reprodução, a configuração visual de anonimato do Ator específico (KRESS; van LEEUWEN, 2006, p. 64) permite inferir que os braços e mãos que aparecem no vídeo podem ser os de qualquer um que está assistindo ao procedimento. Essa leitura é enfatizada pelo recorrente ângulo alto (57\%) e pelo predomínio da distância social de média (45\%) a próxima $(43 \%)$ entre leitor e ações, instrumentos e materiais representados. Dessa forma, a não ocorrência no ângulo baixo, em termos de poder e predominância no ângulo alto, sugere que o espectador é posicionado como alguém capaz de reproduzir os experimentos apresentados. Ainda assim, é possível afirmar que há um relativo equilíbrio entre ângulo alto, caracterizando poder por parte do espectador, e ângulo médio, caracterizando igualdade de poder. A combinação de ambas as categorias parece dar ao espectador uma sensação de capacidade na reprodução do experimento. 
Em relação à distância, há equilíbrio entre proximidade e distância média. Tal característica pode ser interpretada como uma forma de demonstrar, de forma precisa, características importantes das ferramentas utilizadas nos experimentos e formas de reprodução, visando que o espectador possa observar detalhadamente as etapas do protocolo de pesquisa apresentado, tanto em termos dos detalhes das ferramentas de pesquisa (proximidade) quanto à forma como cientistas devem manusear tais ferramentas (distância média). As menores ocorrências de distância em maior grau podem ser relacionadas à necessidade de demonstrar os experimentos de forma mais geral, como apresentar o quadro geral das diferentes etapas do protocolo demonstrado.

Por fim, em relação à atitude, há uma predominância no desprendimento. Tal característica pode ser relacionada à maior possibilidade de detalhamento espacial que o ângulo oblíquo possibilita, caracterizando uma demonstração mais subjetiva do protocolo de pesquisa. Dessa forma, é possível que o experimento seja demonstrado visualmente com mais detalhes em termos da disposição espacial de diferentes ferramentas de pesquisa e etapas de reprodução dos protocolos. Ainda assim, pode-se dizer que há um equilíbrio entre envolvimento e desprendimento, o que pode ser relacionado a dois níveis de representação das etapas de pesquisa: em um nível mais detalhado e objetivo (envolvimento) e um nível subjetivo, voltado à demonstração de diferentes etapas de reprodução e utilização das ferramentas no experimento (desprendimento). Deve-se também considerar que os artigos audiovisuais publicados no periódico JoVE são filmados em laboratório, o que, em termos de espaço físico, possivelmente traz limitações à posição da câmera durante o processo de filmagem. Sendo assim, a ocorrência de ângulos frontais e oblíquos deve ser relacionada a limitações físicas do processo de filmagem em laboratório.

\subsection{A organização retórica em artigos audiovisuais de pesquisa}

Com base na ocorrência dos padrões encontrados descritos anteriormente, é possível mapear a organização retórica do gênero em quatro diferentes seções, com características distintas e objetivos próprios.

Primeiramente, a seção Justificativa, que caracteriza-se por orações declarativas, fornecendo informações a respeito da relevância do estudo apresentado e Demanda, igualdade de poder, ângulo médio e variações em termos de envolvimento.

Em segundo lugar, a seção Protocolo, que caracteriza-se por Orações declarativas, fornecendo informações a respeito de ferramentas e etapas da pesquisa, orações imperativas e declarativas, demandando atividades na reprodução dos experimentos em três estratégias básicas: modo oracional imperativo, modulação e metáforas interpessoais (SILVA, 2015), e oferta, combinada a variações em termos de poder, distância e atitude.

Em terceiro lugar, a seção Resultados Representativos, que apresenta orações declarativas, fornecendo informações a respeito de resultados encontrados e/ou esperados, orações demandando atividades relacionadas a procedimentos que devem ser refeitos de forma a se obter os resultados esperados e recorrência de orientação e codificação tecnológica.

Em quarto lugar, a seção Considerações Finais, que apresenta orações declarativas, fornecendo considerações a respeito da pesquisa, com o uso do auxiliar 
modal should a fim de demandar serviços em orações declarativas e demanda, igualdade de poder, ângulo médio e variações em termos de envolvimento.

No Quadro 2, apresentado abaixo, ilustramos as predominâncias encontradas em cada uma das seções. De tal forma, é possível perceber que os artigos audiovisuais de pesquisa apresentam uma estrutura similar a artigos experimentais escritos: um total de quatro seções, com funções e características diferentes entre si, porém, uma natureza distinta, visto que tais seções apresentam diferentes enfoques se comparadas entre si, com relação à forma a partir da qual recursos semióticos criam a interação autor/leitor.

Nos artigos audiovisuais, na seção Justificativa, o componente semiótico visual trabalha de forma a dar credibilidade à informação fornecida verbalmente, através de um contato mais direto e pessoal entre o participante representado e o leitor. Na seção Protocolo, temos os componentes semióticos agindo de forma complementar, instruindo leitor aos procedimentos de pesquisa. Na seção Resultados Representativos, os componentes semióticos parecem possuir funções similares: enquanto o componente verbal informa o leitor a respeito de resultados de pesquisa e como obtê-los, o componente semiótico visual fornece ao leitor dados esperados, por meio de recursos visuais típicos em artigos experimentais tradicionalmente escritos, como gráficos, tabelas e figuras (MILLER, 1998), de forma a auxiliar o leitor a visualizar dados e interpretá-los. A seção Considerações Finais repete características da seção Justificativa, acrescentando a demanda de serviços, por meio da modulação, no componente verbal. Acreditamos que o componente visual busca creditar as informações fornecidas e ações demandadas, por um contato mais direto entre o participante representado e o leitor.

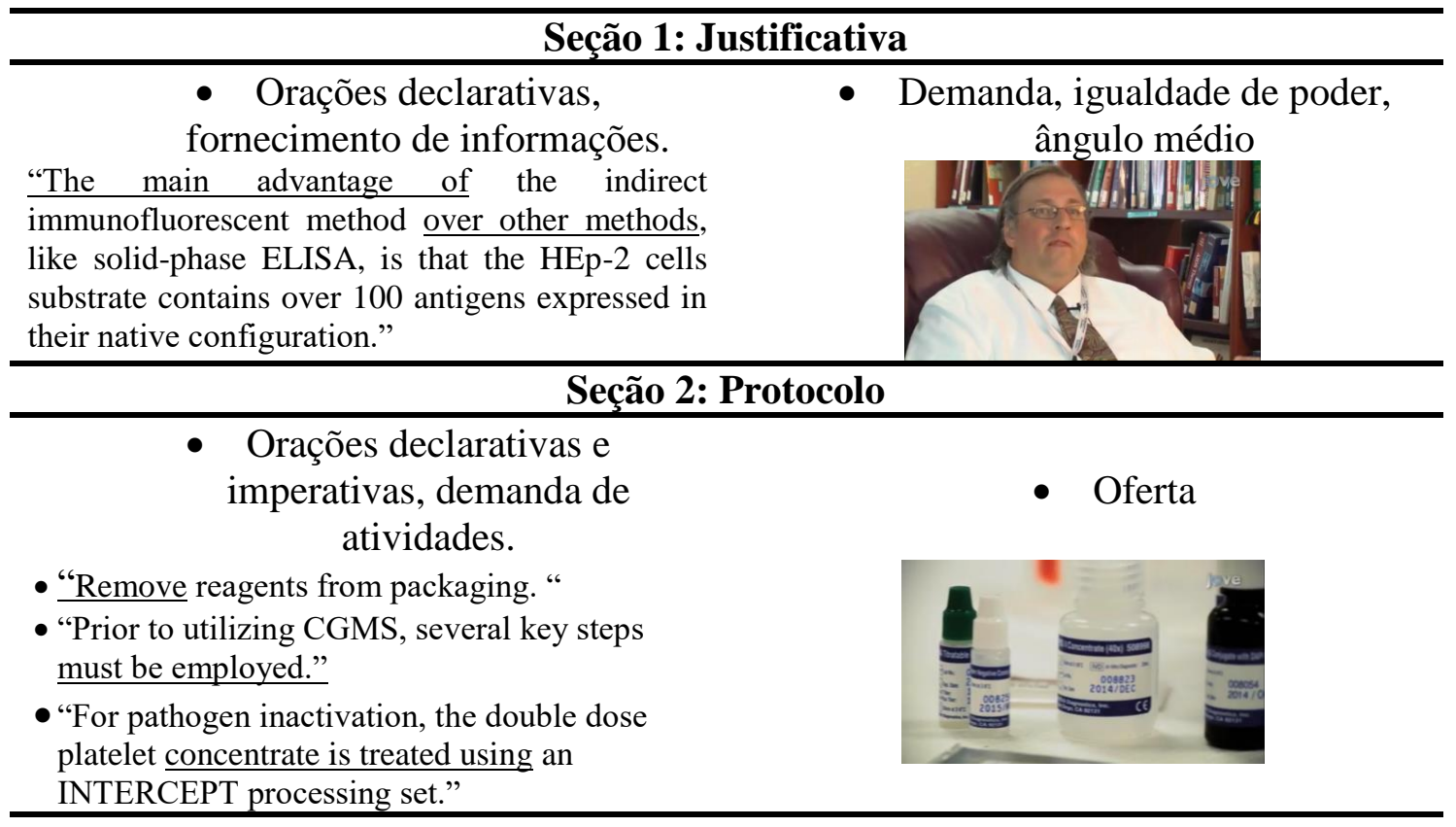

Seção 3: Resultados Representativos
- Orações declarativas fornecendo informações e demanda de atividades.
- Orientação e codificação tecnológica 
"The initial paper intravenous insulin protocols

developed at WMC called for tight glucose

control of 80 to $110 \mathrm{mg} / \mathrm{dL}$ in ICU patients and more liberal glucose control of 95 to $120 \mathrm{mg} / \mathrm{dL}$ in non-ICU patients."

\section{Seção 4: Considerações Finais}

- Orações declarativas; auxiliar modal should.

"After watching this video, you should have a good understanding of how to measure GFR in conscious mice (...)"
- Demanda, igualdade de poder,

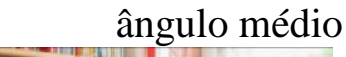

Quadro 2 - ilustração das características recorrentes em cada seção dos artigos audiovisuais de pesquisa

\section{Considerações Finais}

O principal objetivo do presente estudo foi verificar como os artigos publicados no periódico JoVE se configuram interpessoalmente (HALLIDAY, 1994, 2004, 2014; KRESS, van LEEUWEN, 2006), adotando procedimentos e categorias de análise que reconheçam a natureza multimodal do gênero, considerando os dois principais modos semióticos presentes no mesmo - verbal oral e visual dinâmico. Com base na ocorrência de diferentes padrões em termos da interação autor-leitor, foi possível sugerir que artigos audiovisuais de pesquisa se organizam da seguinte forma: Justificativa, Protocolos, Resultados Representativos e Considerações Finais. Sendo assim, apesar de possuírem uma organização retórica semelhante à encontrada em artigos acadêmicos experimentais (SWALES, 1990, 2004), a grande diferença entre os gêneros está na presença e no papel de diferentes recursos semióticos para materializálos.

No tradicional artigo acadêmico experimental, predomina o recurso semiótico verbal escrito, com crescente ênfase para o recurso semiótico visual estático - imagens essencialmente abstratas - codificadas pelo mundo da ciência. No artigo audiovisual de pesquisa, predominam os recursos semiótico verbal oral e visual dinâmico, que exercem papel igualmente relevante na realização do objetivo do gênero, com destaque para imagens essencialmente foto-realistas, menos codificadas pelo mundo da ciência.

Em termos analíticos, consideramos que os resultados aqui exibidos apresentam limitações: a inclusão de apenas duas áreas científicas no corpus final do estudo ainda não permite mapear características ao gênero com mais propriedade. Esperamos também que o presente estudo possa contribuir com a consolidação de artigos audiovisuais de pesquisa como um gênero do contexto acadêmico. Dado o caráter inovador e a riqueza de possibilidades semióticas de publicações nesse formato, é uma pena que o acesso a tal formato de publicação continue restrito.

Em termos pedagógicos, artigos audiovisuais de pesquisa demonstram possuir um grande potencial didático para a área de Inglês para Fins Acadêmicos. Primeiramente, pelo fato de que os artigos audiovisuais de pesquisa publicados no periódico JoVE são aceitos unicamente na língua inglesa - com o grande diferencial de terem o recurso semiótico verbal oral como um elemento essencial na produção de 
significado. É senso comum que o inglês é língua franca da ciência, mas, em termos de publicação, a principal preocupação de pesquisadores "não nativos" sempre foi o recurso semiótico verbal escrito. Entretanto, tendo em vista que os artigos de JoVE podem ser submetidos por pesquisadores do mundo inteiro, o gênero possui um grande potencial em incentivar e motivar discussões a respeito do Inglês como uma língua internacional, conforme proposto por Rajagopalan (2004).

Por fim, é relevante retomar a afirmação de Kress \& van Leeuwen (2006) de que todo texto é multimodal, ou seja, deve ser lido a partir da integração de todos os modos semióticos nele configurados. Assim, consideramos essencial que componentes semióticos sejam compreendidos pela forma com que, unidos, constroem o significado no texto, e não de forma isolada. Afinal, o texto multimodal é constituído através da intersecção dos diferentes recursos semióticos e suas idiossincrasias - suas funções, capacidades, informações específicas que buscam transmitir e a forma com que o fazem - dentro das peculiaridades e limitações de cada recurso semiótico específico. Nesse sentido, sugerimos a pesquisadores na linguagem multimodal que é relevante reconhecer a função que cada recurso semiótico exerce no texto, mas enxergando o significado do texto através da intersecção dos recursos semióticos.

\section{REFERÊNCIAS}

CAZDEN, C.; COPE, B.; FAIRCLOUGH, N.; GEE, J.; et al. A pedagogy of multiliteracies: designing social futures. Harvard Educational Review, v. 66, n. 1, p. 092, 1996.

FAIRCLOUGH, N. Discourse and social change. Cambridge: Polity Press, 1992.

Routledge, 2003. Analysing discourse: textual analysis for social research. London:

HALLIDAY, M. A. K. An introduction to functional grammar. 2 ed. London: Edward Arnold, 1994. An introduction to functional grammar. 3. ed. Revised by

Christian M.I.M. Matthiessen. London: Arnold, 2004. An introduction to functional grammar. 4. ed. Revised by

Christian M.I.M. Matthiessen. London: Arnold, 2014.

HENDGES, G.R. Tackling Genre Classification: The Case of HTML Research Articles. Tese de Doutorado. Universidade Federal de Santa Catarina, Florianópolis, 2008.

O artigo acadêmico no contexto digital: desafios para pesquisa e para o ensino de línguas para fins acadêmicos? I Congresso Nacional de Línguas para Fins Específicos, 15 a 17 novembro de 2010. Vitória: Universidade Federal do Espírito Santo, 2010.

Análise Crítica de Gêneros e implicações para os multiletramentos. Projeto de pesquisa, Registro GAP/CAL n ${ }^{\circ} 031609$. Centro de Artes e Letras, Universidade Federal de Santa Maria, 2012a.

. Uma análise crítica de gênero de artigos acadêmicos audiovisuais: implicações para o multiletramento no contexto acadêmico. Projeto de pesquisa. Edital No 025 /2012 PIBIC/CNPq/UFSM. Centro de Artes e Letras, Universidade Federal de Santa Maria, 2012b. 
HENDGES, G. R.; NASCIMENTO, R. G.; MARQUES, P. M. A gramática da imagem como ferramenta na análise crítica de gêneros midiáticos. In: SEIXAS, L.; PINHEIRO, N. F. (Orgs.). Gêneros: um diálogo entre comunicação e Linguística Aplicada. $1^{\mathrm{a}}$ ed. Florianópolis: Insular, p. 241-274, 2013.

IEDEMA, R. Analysing Film and Television: a Social Semiotic Account of Hospital: an Unhealthy Business. In The Handbook of Visual Analysis (van LEEUWEN \& JEWITT). 2001, p. 183-204.

JOVE. Archive. Disponível em: <http://www.jove.com/archive> ; acessado janeiro de 2015a. 2015b.

Publish. Disponível em: <http://www.jove.com/publish>; acessado março de Instructions for Authors. Disponível em

<http://www.jove.com/files/Instructions_for_Authors.pdf> ; acessado em abril de 2015c. . Video Produced by Author Quality Criteria. Disponível em:

<http://www.jove.com/files/media/AuthorProducedCriteria.pdf>; acessado em abril de 2015d. $2015 \mathrm{e}$.

About. Disponível em <http://www.jove.com/about>; acessado em maio de

Frequently Asked Questions. Disponível em:

<http://www.jove.com/publish/submission-faq >; acessado em setembro de $2015 \mathrm{f}$.

. Contributing Institutions. Disponível em: <http://www.jove.com/institutions>;

acessado em setembro de $2015 \mathrm{~g}$.

JoVE Medicine. Disponível em:

<http://www.jove.com/search?exclude_sections $=0+1+2+11+12+13+15+14+29+16>$; Acesso em: 09 nov., 2015h.

JoVE Biology. Disponível em:

$\langle$ http://www.jove.com/search?exclude_sections $=1+2+4+11+12+13+15+14+29+16>$; Acesso em: 09 nov., $2015 \mathrm{i}$.

KRESS, G.; van LEEUWEN, T. Reading images: the grammar of visual design. 2 ed. London: Routledge, 2006.

MILANI, V. G. Relações intersemióticas em artigos audiovisuais de protocolo de pesquisa de biologia. Dissertação de Mestrado. Universidade Federal de Santa Maria, Santa Maria, 2015.

MOTTA-ROTH, D. Questões de metodologia em análise de gêneros. In:

KARWOSKI, A. M.; GAYDECZKA, B.; BRITO, K. S. (Orgs.). Gêneros textuais:

reflexões e ensino. 2. ed. revista e ampliada, p. 145-163, Rio de Janeiro: Lucerna, 2006.

Análise crítica de gêneros: contribuições para o ensino e a

pesquisa de linguagem. D.E.L.T.A., v. 24, n. 2, p. 341-383, 2008.

MOTTA-ROTH, D.; HEBERLE, V. A short cartography of genre studies in Brazil. Journal of English for Academic Purposes, v. 19, n. 2, p. 22-31, 2015.

RAJAGOPALAN, K. The concept of 'World English' and its implications for ELT. ELTJournal, v.58, n.2, p.111-117. Oxford University Press, 2004.

SHEPHERD, M.; WATTERS, C. The evolution of cybergenres. Proceedings of the 31st Annual Hawaii International Conference on System Sciences, 1998.

SILVA, T. Recursos Interpessoais em Artigos Audiovisuais de Pesquisa. Domínios de Lingu@Gem, v. 9, p. 150-161, 2015. 
SILVA, T. C.; CABRAL, S. R.; HENDGES, G. R. . Uma análise comparativa entre um artigo audiovisual e um artigo tradicional: explorando engajamento no contexto acadêmico. Expressão (Santa Maria), v. 2, p. 183-192, 2015.

SOUZA. M. M. Análise crítica de gênero: significados ideacionais em artigos acadêmicos audiovisuais de protocolo de pesquisa. Dissertação de Mestrado. Universidade Federal de Santa Maria, Santa Maria, 2015.

SWALES, J. M. Genre analysis: English in academic and research settings. Cambridge: Cambridge University Press, 1990.

Research genres: exploration and applications. Cambridge:

Cambridge University Press, 2004. 